I T H A K A R E P O R T

COMMISSIONED BY JSTOR

\title{
Scholarly Communications in the Education Discipline
}

A Report Commissioned by JSTOR

Created March 14, 2008

Ithaka Strategic Services

Authors:

Sabrina Manville and Kirby Smith 


\section{NO T E}

This is an edited version of a study commissioned by JSTOR in 2006. It is being shared as the research presented here may be of interest to others in our community or beyond. For more information about this report or others in this series, please contact Heidi McGregor, Director, Marketing \& Communications (heidi.mcgregor@jstor.org). 


\section{I . E X E C U T I V E S U M M A R Y}

Ithaka undertook a study of the field of education research, begun in December 2007 and completed in March 2008. This study was commissioned by JSTOR to: (1) understand how research is conducted and disseminated in the discipline, and (2) identify the relative importance of various resources. The study draws, first, on interviews with faculty members, librarians, teachers, students, and researchers.

Interviewees were chosen to represent a diverse range of institution sizes and types, disciplinary focuses, and career stages. In addition to these interviews, the study draws on quantitative analysis on usage and citation data from JSTOR, and on secondary research.

Research in education is interdisciplinary, and can address a range of audiences from practitioners and policy makers to scholars. While scholars based in schools of education sample the subjects and practice of many subfields, we found that they identify primarily as scholars of education, rather than with their subspecialty or methodology (e.g. psychology, economics, or policy).

The difference between training future teachers and conducting research that is intended for a scholarly audience leads to the broad spectrum of activity and writing that occurs in education schools. In addition, researchers outside academia use another set of resources and methods to support their work. We found that the production and use of research in education could be understood in terms of four key areas of activity, each employing distinct methodologies and resources:

- Academic research: Research that takes place in education schools and other departments that investigates issues relating to education. This research encompasses a variety of disciplinary and methodological approaches.

- Practitioner preparation: The training of future (or current) teachers, counselors, and administrators.

- Non-academic research: Research occurring in education-focused think tanks, non-profits, and corporations.

- Practice: The on-the-ground work done by teachers, counselors, and administrators based in schools or school districts.

Notably, education researchers may engage in more than one of these activity areas simultaneously, or over the course of their career.

Peer reviewed journal literature is the dominant form of scholarly communication for academic research in education, and journals focused primarily on education are more important to the field than disciplinespecific titles (for example, a general economics journal that might publish some articles relating to education). Conference proceedings are also frequently cited in education literature, though other unpublished materials such as working papers and gray literature are referenced less often. Research literature is used in varying degrees in the preparation of future teachers; publications known to bridge the gap between research and practitioners, ranging from peer reviewed journals to trade publications and best-practice manuals, are particularly important here. Researchers based in think tanks or non-profits often use research literature through resources like JSTOR, depending on their degree of institutional access. They also, however, closely follow the work done in organizations like their own, via email lists or other networks. 


\section{I I I N T R O D U C T I O N}

This study is unique compared to other discipline studies Ithaka has conducted on behalf of JSTOR because of the sheer size of the field of education, its diversity across disciplines and audiences, and its dual nature as a professional and academic field. The number of students involved in the academic study of education is vast. 78\% of all four-year colleges and universities have a department or a school of education; there are as many as 1,200 of these in the US. ${ }^{1}$ In 2004-5, almost $30 \%$ of all master's degrees $(167,500)$ and almost $15 \%$ of all doctoral degrees $(7,681)$ were awarded in education. These outnumber all other types of master's degrees (including MBA's) and all other categories of doctoral degrees. Needless to say, people involved in education research and practice are found in many non-academic institutions as well, including think tanks, government offices, corporations, and schools and districts themselves.

The work that goes on in schools and departments of education is so diverse that the field is not easily characterized. Arthur Levine, former president of Teachers College and the author of a series of reports on the state of education schools, calls the field "amorphous... a field without focus or boundaries." He argues that the evolution of programs in education schools has been haphazard, subject to the vicissitudes of other fields like psychology and sociology. The relative youth of the field (it took form in the nineteenth century) has also allowed it to be shaped and expanded in scope by innovators in many different disciplines. ${ }^{2}$ The variety of programs within education schools further complicates easy characterization of the field. These schools are institutions that support academic work as well as professional schools supporting careers ranging from school counselors, to classroom teachers at all levels, to administrative and management positions. Unlike at business schools, where parallel challenges might exist, education schools confer multiple types of degrees, with little standardization across programs. These offerings include doctoral degrees of two kinds ( $\mathrm{PhD}, \mathrm{EdD})$, master's degrees, BA's, and teaching certificates. Further, while the EdD was originally created "to establish a professional degree for education practitioners, differentiated from the research-oriented $\mathrm{PhD},{ }^{, 3}$ in practice the degrees are defined idiosyncratically at each institution.

This paper will begin by describing the investigative approach we took for this study. We will then describe in further detail the landscape of scholarship in education, and the different methodologies employed by scholars of education. We will briefly discuss the divide between research and practice, one of the great challenges faced by education scholarship. This theme will recur throughout our study, as scholars and practitioners alike wrestle with the relationship of research to what occurs on the ground in the education system. We will then transition to a discussion of the activities supported by education research: academic research, practitioner preparation, non-academic research, and the work of practitioners themselves. For each we will describe the materials and processes that are most important.

\footnotetext{
${ }_{1}^{1}$ Arthur Levine, Educating Researchers (Washington, DC: The Education Schools Project, 2007), p. 6. Available at http://www.edschools.org/EducatingResearchers/

${ }^{2}$ Levine, pp. 27-28.

${ }^{3}$ Levine, p. 40. Levine also notes that there was an underlying political reason for this new degree: researchers' disapproval of the presence of practitioners-in-training and practitioner content (which was substantial) in their doctoral programs.
} 


\section{I I . M E T H O D O L O G Y}

We conducted both primary and secondary research in the course of this study. The primary research consisted of 27 interviews with scholars, librarians, teachers, students, and researchers. Our interviewees were identified through personal contacts as well as online research. First, we identified key subject focuses (roughly the same as the sub-disciplines we had identified in the field, which are described below) and found scholars in departments known for their strengths in these areas (according to US News and World Report, as well as Academic Analytics). In addition to these scholars, we reached out to instructors and teachers in departments who were likely to be focused heavily on practitioner training rather than a combination of practice and research. We chose to contact professors on the basis of their biographies on department websites, choosing a mix of contacts at various stages in their careers and at different types of institutions (including public and private, of varying sizes, and both research-intensive and non-research-focused institutions). Next, we identified graduate students and practitioners (teachers and researchers) through our personal networks and those of some initial interviewees. Many of these interviewees had experience in academic institutions as well as in practitioner settings, which provided valuable perspective.

JSTOR usage data, as well as findings from the Ithaka 2006 Faculty Survey, helped to frame our initial hypotheses and supplemented the qualitative data. We also conducted secondary research from a variety of sources including data sets, websites, and publications. Where appropriate, the sources are referenced in the body of this report. 


\section{V • A N I N T E R D I S C I P L I N A R Y A N D C C O M P L E X F I E L D}

Scholarship in schools of education is related to a broad range of disciplines, from the history and social theories of education, to economics, statistics, or the natural sciences. For the purposes of this study, we developed a taxonomy of education research which can be used to understand the scholarly literature and, in many cases, researchers' fields of study. The taxonomy is based on a variety of sources, including interest divisions within the American Educational Research Association (AERA), the categorizations provided by the NORC Survey of Earned Doctorates, the specialties highlighted by US News and World Report and by Academic Analytics, and through our own understanding of the field. We divided the field of education research into five broad subfields, some of which are further subdivided (see details in inset at right). We will refer to these categories at various points in our report, particularly in our discussion of publications in education.

\section{Methodologies in Education Research}

When we began our study, we expected to find that scholars working in these subfields would have substantially different research processes, and would rely on unique sets of resources. It seemed possible, for example, that scholars would align closely with the methodologies used by their peers in parallel disciplines (e.g., that an educational psychology professor would work in a similar way to a psychology professor in the faculty of arts and sciences, or that an educational sociologist studying the context of education would aspire to publish in the same journals as her colleagues in the university's sociology department). However, we were surprised that many of the faculty we interviewed self-identified primarily as scholars of education - not as sociologists or psychologists - regardless of their disciplinary training or specialty. For example, one associate professor with whom we spoke holds a $\mathrm{PhD}$ in educational psychology, but rarely works with other psychologists. She feels more in touch with anthropologists, sociologists, ethnographers, and other scholars with similar content interests, rather than with scholars with a similar disciplinary background.

Several scholars speculated that the divide between theoretical research (which might occur in a discipline-focused department) and applied research (which occurs in a school of education) influences this pattern of scholarly identification. A PhD student studying the economics of education said that she chose her program because of her interest in the real-world application of economic principles.

"Economics departments in general don't really value applied research as much as theoretical research. I thought I would be more supported in my interests" in a school of education, she said. An associate 
professor of education at another education school agreed that the character of education schools and the goal of education research makes education very different from other departments. She says that while a political scientist might use education as an example in the study of political dynamics, an education scholar is interested in fixing the education system. This difference can lead to silos of scholarship and information.

The literature examining education research suggests that education scholars "are free to deal with educational questions from whatever disciplinary perspective or methodological approach they find appropriate," and are "free to be as eclectic as they wish in the way they choose to intermingle disciplinary perspective or methodological orthodoxies," according to David Labaree. ${ }^{4}$ Of course, there are real distinctions between the work done by scholars looking at educational history and that done by scholars researching educational psychology. However, education researchers switch freely between these modes during their career, and can employ multiple approaches even when thinking about individual questions.

Though some scholars hew closely to a particular subfield or disciplinary focus, many education researchers sample the subjects and practices of many subfields. We heard that a more salient division within education scholarship is that between those who use quantitative and those who use qualitative techniques.

Quantitative research relies heavily on statistical analysis to detect trends and causal relationships in education. Often, scholars taking a quantitative approach will make use of the extensive amounts of publicly available data produced by governments and school districts. Other times, they will collect their own data through designing and administering surveys. Sophisticated analytical approaches are used to understand this data. Quantitative methods cannot be used to answer all types of questions, however. One scholar told us that it is "really difficult" to conduct quantitative research about some subjects because of the challenge of controlling for all variables and conducting randomized trials of students. ${ }^{5}$ Qualitative research makes use of case studies, ethnographic techniques, and interviews to answer the many questions about education that cannot be addressed through numerical analysis. This work focuses on understanding educational processes in context. Researchers working in this mode spend significant amounts of time in the field, observing classrooms and speaking with students and teachers, and interpreting trends in these findings.

Both qualitative and quantitative research can be broadly described as empirical approaches, but education scholarship includes non-empirical literature, as well. Several scholars we spoke to publish philosophical or conceptual articles that apply social theories to educational contexts. These scholars might rely heavily on scholarly literature to support their work, without themselves engaging in significant amounts of either qualitative or quantitative empirical research.

\section{The Research-Practice Divide}

There are two main sets of activities in education schools - preparing future practitioners, and conducting scholarly research about education. We found that most education professors straddle this divide in their work. Even at the tenure-track level, very few professors in education schools exclusively teach future researchers. Likewise, students - even doctoral students preparing for a career in research - have some

${ }^{4}$ David Larabee, "Educational Researchers: Living with a Lesser Form of Knowledge," Educational Researcher 27:8 (November 1998), pp. 4-12.

${ }^{5}$ The No Child Left Behind Act (NCLB) includes many provisions requiring "scientifically-based" research, which caused much tension in the education field. We heard that "at the federal level there is a push towards" randomized trials and other quantitative research, and away from qualitative methods like ethnography. Education scholars have pushed back against this, according to one interviewee. "For a while after NCLB, a qualitative study was almost a statement of rebellion," she said. 
coursework that is research-heavy, some that is more practically oriented, and many assignments which combine the two.

The research-practice divide extends to the literature produced by education scholars. Many professors believe it is important to disseminate their work to practitioners in some way. One professor of teacher education believes that "education researchers focused on K-12 schools have an obligation to present what they learn to teachers. People who just write for AERJ [American Educational Research Journal] aren't meeting their full expectations." Others scholars are skeptical that these sentiments are widespread; one interviewee said "academics don't really care if teachers read their stuff. Ideally, it would be great if our audience included policy makers, but most education researchers have to admit that no policy makers are paying any attention to their work." He thinks "some teachers might read journal literature, but for the most part they don't."

In any case, tenure proceedings privilege publishing in journals for scholarly audiences, making it difficult for junior faculty to find time to disseminate their work to practitioners. One professor early in her career says that she spends about $70 \%$ of her time publishing in research journals, and about $30 \%$ publishing for other audiences. While she believes strongly in writing for practitioners, she hasn't "made good on that interest" as much as she would like. This constraint seemed to be common in the field. Many of the researchers we interviewed do have some experience spreading their work to non-scholarly audiences, however. They do so by writing for publications they expect reach other groups, and by presenting at conferences and professional association meetings. One scholar suggested that books may be more likely than journal articles to reach teachers, and executive summaries of grant-funded projects may be more likely to reach policy makers. We will address these 'practitioner-friendly' outlets later in the paper.

\section{Trajectory of Scholarly Communication}

Through our interviews, we heard about important trends in the field relating to the influence of electronic resources and the importance of grant-funded research. The increasing use of electronic resources has facilitated the use of materials from other disciplines in education research. It used to be much harder for scholars to keep up with relevant developments not just in education, but also in fields as diverse as psychology, management studies, political science, etc. Several interviewees told us that the growth of electronic resources has enabled them to search more broadly across various disciplines. "I find it much easier to be multidisciplinary in my reading, to read much more broadly in psychology and sociology, for example," one researcher said.

We heard suggestions that collaboration between scholars in education schools and in other departments may be on the rise, as well. A librarian based at an education school told us that he has observed an increase in the number of these partnerships in the last few years, including joint appointments and crosscampus initiatives that transcend disciplinary boundaries.

The growing importance of grant-funded research in education may be influencing this landscape. For example, one education scholar who collaborates closely with scholars in other disciplines on a federallyfunded project told us that "externally funded research is an expectation of faculty members in the field of education." Her school of education is "increasingly funded on external support - colleges and universities always need funds." Grant funding may have some effect on the audience for research, as well. This researcher finds herself directing more of her grant-funded work towards practitioners, or focusing on practical implications. "I think that's part of the nature of funded research," she said. "The funding agencies' expectation is that you'll find ways to disseminate your work to practitioners as well as researchers." 
We also heard hints that the quality and importance of practitioner-focused products may be increasing. Several scholars mentioned that some journals that address broader audiences (policy makers, teachers, and administrators) have improved in quality and may be more visible in the academic world than they had been.

\section{Our Approach}

Because faculty and students at education schools are involved in both scholarly research and professional training, we segment our discussion of materials and processes by these two activities. First, we describe the resources and research strategies that relate to scholarly research. These activities draw largely on scholarly literature, and some gray literature. Next, we address materials used in practitioner preparation. We will describe some of the characteristics of these programs and the resources these professors and students rely on. As we will detail, master's students (and, to a lesser degree, BA students obtaining teaching certification) make use of the research literature in many of their classes. They also make use of another set of resources that focus on the ways in which research can inform classroom experience. Last, we will discuss other users of education literature, including in-service teachers, policy makers, and researchers outside the academy. While these audiences were not the focus of our interviews, we are able to draw some preliminary hypotheses about their research processes and the materials they find useful. 


\section{A C T I V I T I E S A N D A U D I E N C E S I N T H E F I E L D O F E D U C A T I O N}

\section{A. Materials and Processes in Education Research}

Scholars in education schools use a variety of materials to aid in their research, as do students who are engaged in research-related activities.

\section{Journal Literature}

The peer reviewed journal article is the dominant form of scholarly communication in the education field. Regular publication in well-regarded journals is considered essential in tenure proceedings, and journals are the primary vehicle for sharing research with other scholars. The most prestigious education journals are the general research journals published by AERA and by the top education schools. In addition to the six AERA publications, Harvard Education Review and Teachers College Record are read broadly and attract the best scholarship from across the sub-disciplines. Nearly every scholar we spoke to hoped to publish in these journals. "If you publish as an assistant professor in one of those, you pretty much guarantee you'll get tenure," one professor said. Beyond these general titles and others like them, each sub-discipline has its own hierarchy of field-specific journals. There tend to be a few premier publications in any given sub-discipline, which may be considered nearly on par with the general titles in terms of prestige, as well as a wider range of less selective titles.

Although education researchers tend to value education-centric resources above those in adjacent disciplines like political science or economics - likely because many scholars feel only a tenuous connection to a disciplinary specialty or approach - we did see some evidence that journal literature from other disciplines is useful for education researchers as well. Of the 100 journals most frequently cited by journals within JSTOR's education holdings, the majority are explicitly education-centric; AERJ, Review of Educational Research, and Elementary School Journal all appear in the top ten, for example. An analysis of internal citation linking between JSTOR education journals and other JSTOR offerings further reveals that scholarship from other disciplines plays a substantial role in education research. There are 240 journals in 38 disciplines within JSTOR that are referred to by journals in the education collection 25 times or more. While $67 \%$ of these links are to other journals in JSTOR's education collection, a full third of all linked references are to journals not listed or cross-listed in education. The largest proportion of these links $-13 \%$ of the total - is to titles in sociology.

Interestingly, the reverse trend is not as prominent. 576 JSTOR journals cite the education holdings, but only 152 of these cite education journals to a significant degree ( 25 times or more). The vast majority of citations of education journals occur in other education journals. $89 \%$ of all citations within JSTOR to education journals in JSTOR occurred within the discipline. Although education journals have been referenced by a wide range of journals (in 27 other disciplines!), of the $11 \%$ of citations that occurred in journals not listed or cross-listed in education, nearly half of the references appeared in sociology journals, with many other citations in Language and Literature, Anthropology, and Business. It seems that education scholars reach out to use the scholarship of other disciplines more than scholars from other disciplines refer to education research in their work. 
JSTOR Internal Citation Linking - What do JSTOR Education Holdings Cite?

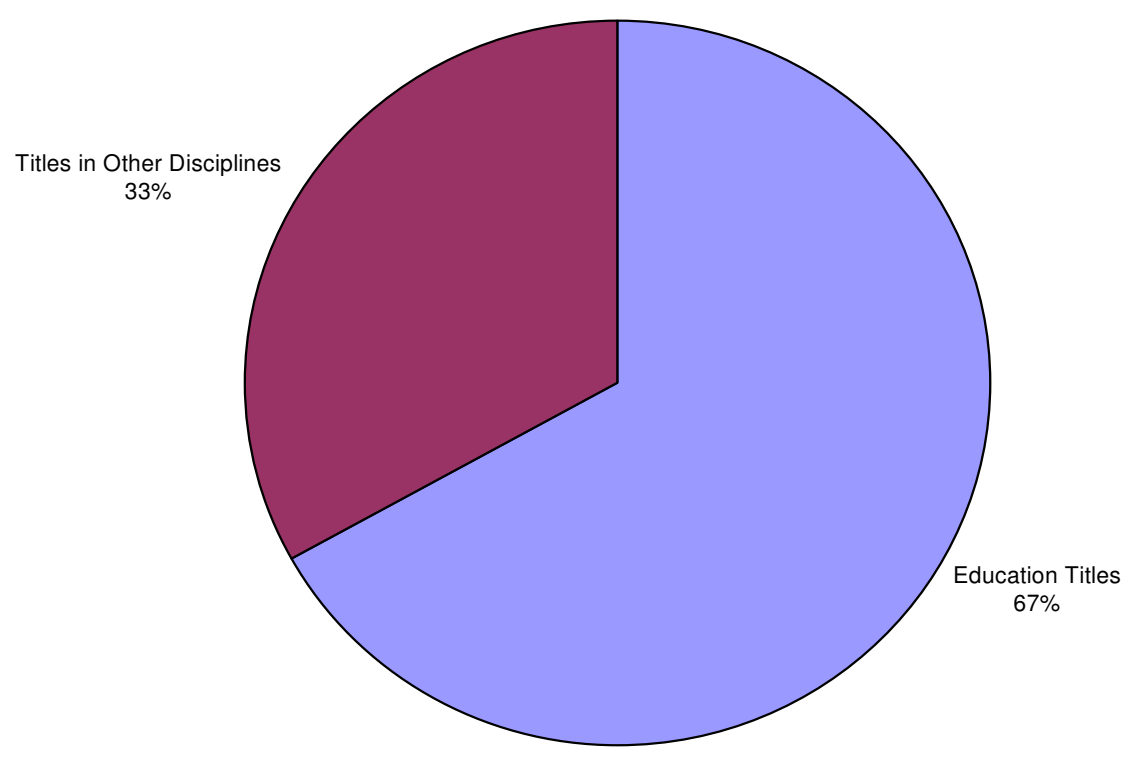

Citations of Other JSTOR Disciplines by JSTOR Education Holdings

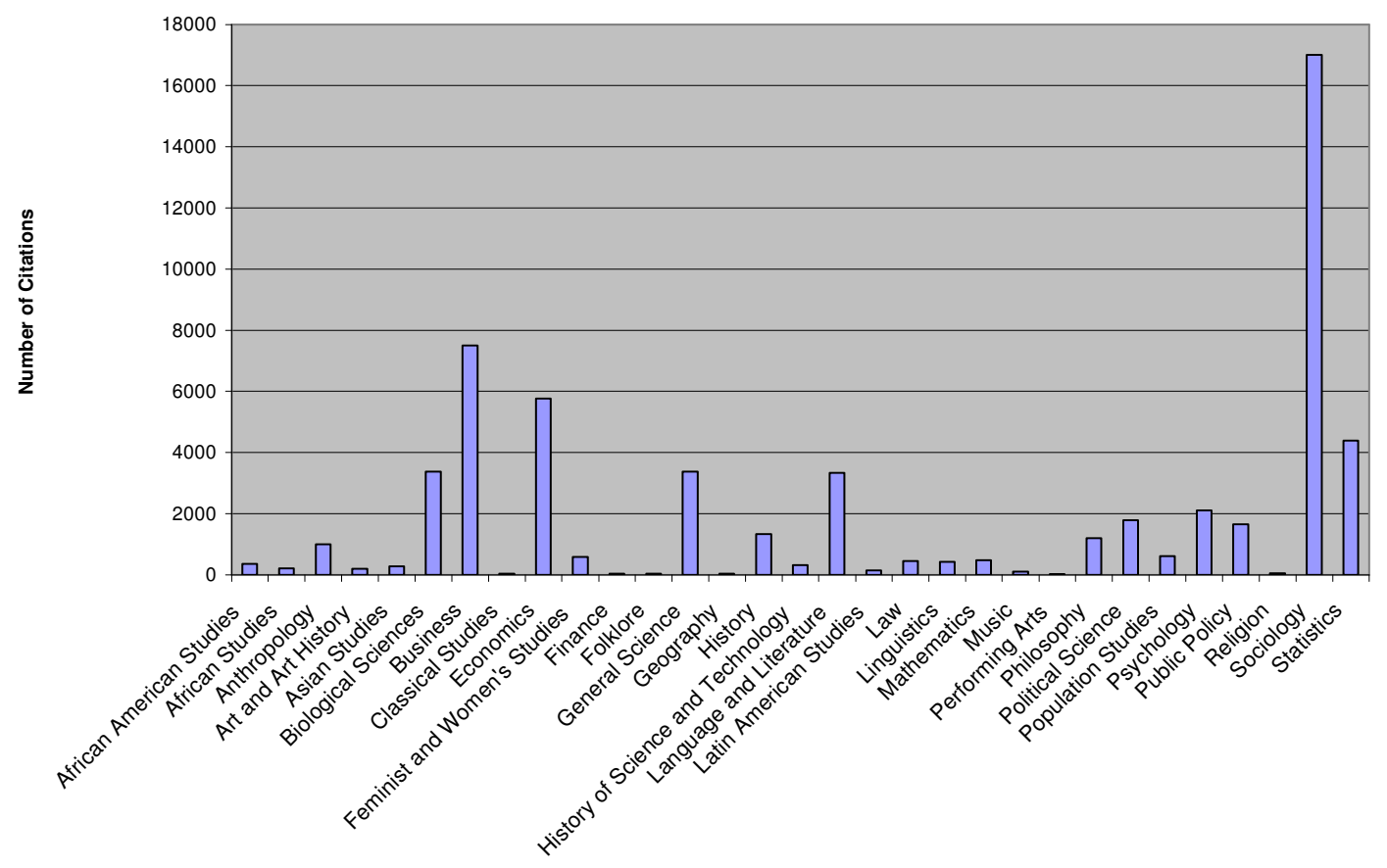




\section{JSTOR Internal Citation Linking - What Cites Education?}

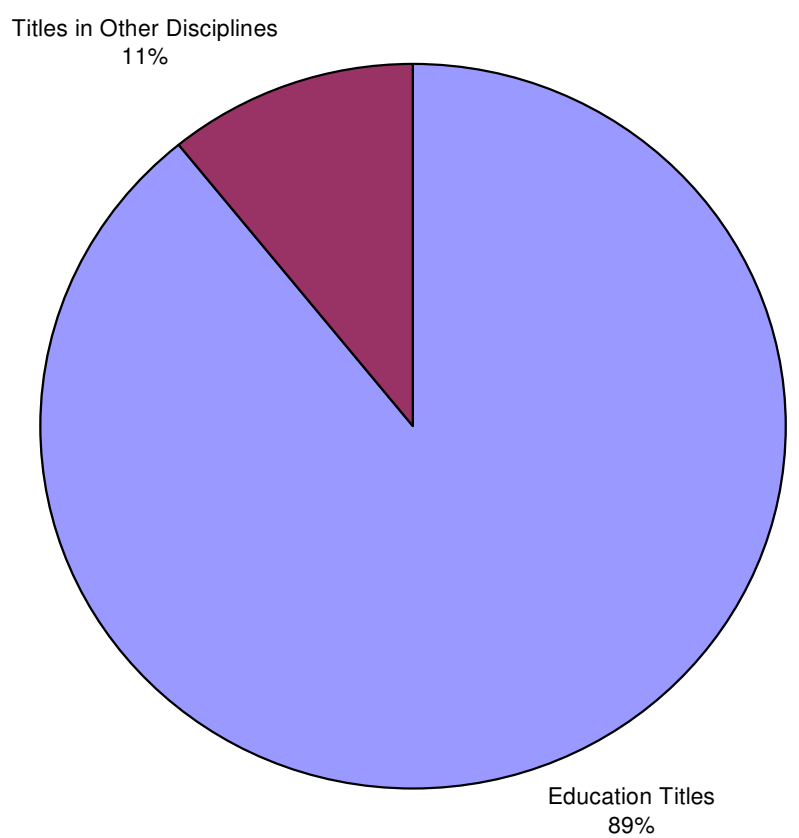

Citation of Journals in JSTOR Education Holdings by Journals in Other Disciplines

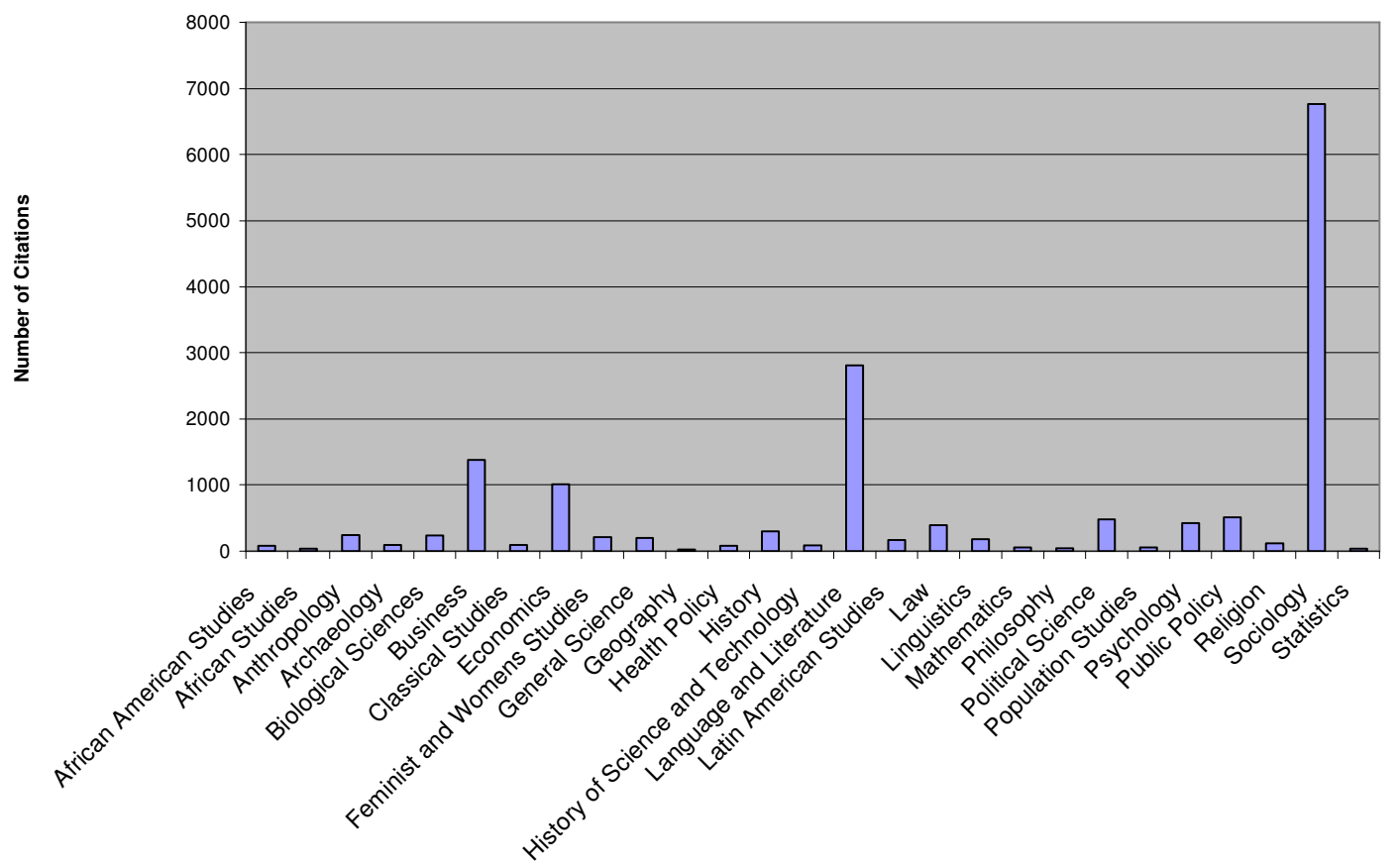


International journals seem to play a relatively limited role in American education scholarship. Because education is so tied to its particular socio-cultural context, we heard, the findings of international studies are not always relevant to work done in the U.S. However, some international journals, such as the Journal of Educational Administration (Australia), and Curriculum Inquiry (UK) do seem relevant to American scholars. Several of our interviewees mentioned that British, Scandinavian, and Australian resources have perspectives and socio-cultural frameworks that can have interesting applications to American work. In addition, international resources relating to certain sub-disciplines that are less context-dependent, like educational psychology or technology, may be of more value to American scholars.

We also heard suggestions that American education journals may have a higher profile abroad than international titles do here. A professor at a Canadian university said that she often uses American resources in her work in part "because the culture is so similar," and in part because the U.S. produces "so much more" education scholarship than Canada. One interviewee who is currently collaborating on a project with colleagues from Europe says her research partners have been pushing to get their work published in American journals. The importance of U.S. journals abroad is supported by the JSTOR usage data; of the top 100 institutional users of the education collection, 44 are international.

\section{Books}

Although books are not as important as journal articles in education scholarship, ${ }^{6}$ nearly all the scholars with whom we spoke said that they do use them on occasion in their research. The books they use fall into several different categories. First, education literature has a "canon" of classic volumes of influential theory that are cited again and again. Texts by Dewey and Piaget seem to be important to education scholarship in much the same way as Darwin was considered essential by some of the scholars interviewed for a similar study Ithaka conducted on behalf of JSTOR on the biosciences discipline. ${ }^{7}$

Edited volumes are used by many of the scholars we interviewed, while monographs are used to a much lesser degree. (One researcher mentioned that "many subjects in education don't lend themselves" to book-length studies.) Many scholars wish that they had access to more of these books online. One professor infrequently incorporates books into her teaching because she does not want to make students purchase an entire volume only to use one chapter. Another scholar says that while she "wouldn't print out a whole e-book," she'd love to be able to download particular chapters to see if it was worth securing the entire volume through interlibrary loan.

Several scholarly societies publish (or collaborate with commercial publishers to produce) academic handbooks on the state of research in particular fields. The Handbook of Research on Teaching, the Handbook of Child Psychology, Advances in Child Development and Behavior, the Handbook of Reading Research, and the Handbook of Research on Mathematics Teaching and Learning are all among the top 10 most-cited books by the education journals in JSTOR's education collection. Many of these handbooks are closely tied to specific sub-disciplines; for example, in educational and counseling psychology, the Handbook of Vocational Psychology, the Handbook of Counseling Psychology, and the Handbook of School Counseling are important texts. These volumes are only available in print, and several scholars said they always buy new editions when they are released.

\footnotetext{
${ }^{6} 50 \%$ of education respondents in the 2006 Faculty Survey had never published a book; $70 \%$ had published at least one article in the past 5 years. 7 Of the 153 books that were cited frequently (more than 150 times) by JSTOR's education holdings, four were written by Dewey, and four by Piaget.
} 


\section{Conference Proceedings}

Conferences are of great importance to the community of education scholars. Our interviewees rely on conferences to allow them to connect with others working in their field and to keep up-to-date on research trends. The AERA conference is the largest and most well-known of these. Many sub-disciplines have their own conferences, as well, such as those sponsored by the Association for the Study of Higher Education or the Association for Engineering Education. Some scholars attend the conferences in other disciplines. Smaller regional conferences as well as conferences hosted by teacher associations can, we heard, help connect researchers to practitioners. The American Association of Colleges for Teacher Education, the Center on Education and Work, and the American School Counseling Association all hold conferences that we heard would fall into this category.

The proceedings of education conferences - particularly the AERA conference - are frequently cited by education researchers. In fact, if conference proceedings from various years were considered as a whole, AERA proceedings would be one of the top 100 most-cited resources by JSTOR's education journals. Because the peer review process can be lengthy, citing conference proceedings is sometimes the only way to refer to the most recent developments in the scholarship. Despite their importance, there is no single place where conference proceedings are electronically held. Some scholarly associations may circulate them - for example, the Association of Supervision and Curriculum Development has a newsletter for members that one interviewee found helpful - but many scholars rely on informal networks to access these materials. One interviewee mentioned that conference papers occasionally appear in ERIC searches, but this does not seem to be a reliable way to access them.

\section{Data Sets}

Data sets are of great importance to certain sub-disciplines that use more quantitative approaches to study education. Vast amounts of data exist on student achievement scores, demographic patterns, and finance models. Some of this information is publicly available through government sources; for example, many faculty mentioned that they frequently turn to the federally-sponsored National Center for Education Statistics (NCES) for highly-reliable data. Other data sets are collected by scholars and disseminated through informal networks. "A lot of the databases we gather are through connections between people," one interviewee told us.

\section{Pre-publication Literature}

Few of our interviewees use peers' pre-printed articles, and those who do generally obtain copies through personal contacts and informal networking. The field of education does not have a central repository for these papers comparable to, for example, arXiv for physicists. Almost no one described relying on working papers as an important resource of information. ERIC does accept contributions of non-peer reviewed literature and working papers - but no one we spoke to had contributed a working paper to ERIC in the past, and few knew that contributing was a possibility.

\section{Gray Literature}

A wide variety of organizations - think tanks, governmental groups, and NGO's, for example - publish education-related research outside the academy. A few of our interviewees said they use this material for their academic research, though this body of material is less important in the academic community than other resources they use, and much harder to find.

This decentralization was confirmed by those of our interviewees who work at the organizations which produce such reports. One former researcher at an education-focused non-profit has a $\mathrm{PhD}$ and produces work that is of a scholarly quality. He rarely takes the time, however, to submit to peer reviewed journals because he does not have the incentives that a tenure-track professor would have to do so. He said he 
thinks getting his work into Education Week is a great way to communicate his findings because "at least everyone working on the subject now, if not in the future, is going to see it." He occasionally presents at AERA or other scholarly conferences as well, but did not appear to have a consistent approach to publicizing his work. A researcher at another think tank commented that her organization has no method for publicizing its own research outputs and often relies on its personal networks to do so.

\section{Research Processes}

It is perhaps the diversity of the field which accounts for the variety of research processes we encountered in our work. One might expect ERIC, which includes materials of all kinds and from all sub-disciplines, to be a major force in the education research process. Its name recognition is very strong: every one of our interviewees was familiar with ERIC and had used it at some point. Despite this, and despite its goal to be a comprehensive resource, it is not the dominant "first stop" in education research. Some faculty with whom we spoke refuse to use ERIC anymore, or use it only as a last resort. They feel that ERIC searches turn up volumes of non-peer reviewed work that is difficult to sift through, and prefer to use more strictly scholarly search tools.

The 2006 Faculty Survey showed database-like resources had high awareness among education scholars, and this was confirmed by our interviews. Many of the scholars with whom we spoke list PsycInfo as one of the databases they rely on. Other resources mentioned include Education Full Text, and EBSCO's education product.

Many scholars of education do rely on Google Scholar or their library's website search functions to track down citations. It seems quite common for scholars to search by author for the latest work in their field, and to then track down supplemental sources by following citations in the bibliography of high-quality articles. Several scholars mentioned that they use Web of Science for this; others look up citations in search engines. The scholars we spoke to have a strong preference for search techniques that allow them to quickly click through to full-text PDFs. Few of our interviewees had a strong preference for one source of PDFs over another.

Although personal contacts, informal networks, and conferences play an important role in the research process, we did not hear of widespread use of community-wide research-sharing resources or socialnetworking sites. 


\section{B. Materials and Processes in Practitioner Preparation}

Students in education schools have a wide variety of backgrounds and career goals. Professors we spoke with had, for example, students who were teaching full-time while getting their master's degree at night, students who had never been in a classroom but who were training to teach, students preparing for a career in academic research, former principals and district administrators studying for professional development purposes, school counselors-to-be, and many others. While program content varies significantly between institutions, a few generalizations can be made about the degrees offered by education schools. Doctoral students may be preparing for a research appointment at an education school or another organization, or for a career as a school administrator or curriculum coordinator at the district level (many more doctoral students are working toward practical careers than research appointments, however). Master's students are generally pre-service or in-service teachers hoping to develop their skills, and to obtain credentials that allow them to advance up their district's pay scale. Undergraduate students take classes to receive teacher certification. Many practitioner-students at the graduate level continue to work in the classroom while pursuing their degrees in the evening.

It is common for practitioners-in-training at all levels to be exposed to research materials during the course of their studies. One professor spoke for many of our interviewees when she explained that "no matter what [kind of degree] you want to get, everyone needs an understanding of the history of the development of education, the development of different research practices and methods." The degree of exposure varies, however, with the program or degree type, the course content, and the professor's teaching philosophy. In general, doctoral students are required to do more original research and are expected to incorporate a higher level of analytical thinking in their work. Master's students, we heard, may have some opportunities to make the connection between research and practice. Undergraduate students are focused more strictly on earning their certification and preparing for their practical studentteaching experiences and first jobs. From our conversations with faculty, it seems that undergraduates are exposed to somewhat less research literature, and see it in more controlled settings (through a course packet or posted on a course management system, for example).

Doctoral students (who may be destined for careers in either research or practice) are exposed to a significant amount of scholarly literature in preparation for their dissertations. Students on both the research and practice tracks generally take their classes together, although there is a move, led in part by the Carnegie Project on the Education Doctorate, to make the content of research- and practice-focused programs more distinct.

Many professors agreed that while they do not expect their master's level students to keep up-to-date with research literature after they graduate, they want them to be familiar enough with education scholarship that they can be "literature consumers" when they hear about trends and programs through other channels. Professors take a wide variety of approaches to accomplish this goal, however. Those who fall on the research-heavy side of the spectrum assign projects - in-depth literature reviews, for example - similar to those that students in doctoral programs must complete. These professors expect their students to track down research literature on their own and substantively engage with it. As one professor of teaching methods in English said, "Although there is a pretty robust body of literature that says that pre-service teachers have no interest in social theory, that they want hands-on work, that's not what I do because I feel they can get the practical stuff in different ways."

Other professors prefer to give their students assignments that focus on the application of research in practical settings. One professor has her students apply research literature to concrete problems in their own teaching in a course on classroom management. "They develop theories about what is going on in the 
classroom and write a proposal about how to address it. Then they carry it out, and analyze the data they collect afterwards." Some courses, particularly for undergraduates or master's students also earning their certification, are more practically-focused. One professor said that "I don't give them as much research, to be perfectly honest, as field-experience stuff. When I get a hold of them they're more interested in pedagogy and practical applications - best practices." Although his students may have taken more theoretical classes, like educational psychology, earlier in their studies, by the time he works with them, "they're sort of past the research stage."

While students in these programs sometimes have to seek out research literature on their own, many may access it primarily through course packets and articles posted on their class's course management systems. The chair of a master's program at a large public university instituted a library training session for all students, but implied that this may be somewhat rare. A recent graduate of a master's program said that her professors gave the students cursory library orientations and guidance on how to search for materials, but that because the professors didn't really incorporate that much research into the classes, she only had to find scholarly resources for a few term papers. "I had to use digital resources for my master's thesis," she said, "but other than that they didn't really come up."

While research literature is certainly an important component of master's and undergraduate programs in education, it seems that in some cases this use may be somewhat shallow, even if the volume is considerable because of the number of students in the field.

\section{Journals}

Practitioners-in-training seem to be less interested in the details of sophisticated research literature and statistical analysis than they are in finding take-home principles that they can apply easily to their teaching. A recently certified teacher told us that the practical resources and case studies used in her courses were much more valuable than research literature was. She connected more with practical articles written by teachers than with those written by scholars. However, as described above, exposure to some research literature is still an important component of most practitioner-preparation programs.

\section{Secondary Literature and Trade Publications}

A variety of non-peer reviewed publications have emerged that seek to translate and synthesize research and scholarship for a practitioner audience. The best of these publications include articles written by scholars explaining the application of their own work to a practical audience, or articles which are produced by authors who work closely with scholars to ensure that the content is rigorous and meaningful. Phi Delta Kappan was cited by many of our interviewees as a leading example of this category. Others with this reputation included Educational Leadership and Educational Researcher.

Many professional associations, such as the Association for Supervision and Curriculum Development or the National Science Teachers Association, publish practitioner-friendly work. The National Council of Teachers of English, an American professional association, publishes twelve periodicals targeted toward a range of grade level instructors. Several in-practice teachers with whom we spoke said that publications like these were the most valuable resources they used in their undergraduate and graduate programs. Trade publications also help provide interpretations of research in forms designed to be accessible for practitioners.

\footnotetext{
${ }^{8}$ This teacher suggested that for many of her classmates who were teaching full-time while obtaining their degree, accessing research literature could be difficult. They had little time to
} do research before and after their evening classes, and could not access many of the library's resources from home. 


\section{Books}

While books are not the primary medium for scholarly communication in education, they seem fairly common in teacher preparation programs. These include best-practice manuals and books published by teacher associations or general publishers like Scholastic. 


\section{Materials and Processes for Research outside the Academy}

Much education research occurs outside the academy, in non-profits, think tanks, and for-profit education-related companies. The primary audiences for the outputs of this work are policy makers and practitioners. Academics are not seen as a primary target, so this research, while often quite rigorous, is rarely published in peer reviewed journals. Many of the materials and processes used by these researchers, however, are similar to the ones used by academics.

\section{Journals}

Access to journals is an issue for researchers who are not based in universities; nevertheless, it seems that those who have access do make substantial use of them. A researcher at a Washington, DC, think tank told us that "JSTOR is widely used" there, and she has used it extensively in her work. "I often look in JSTOR directly," she said, though occasionally, she will use Google Scholar if she has a specific article in mind, and she finds EBSCO useful in other situations. "The driving force is really where I can get the full-text [article]." She subscribes to the AERA journals, Reading Research Quarterly, and the Journal of Education for Students Placed At Risk (a research publication, but which has substantial practical writing), among others. ${ }^{9}$

\section{Gray Literature}

Scholars in think tanks seem to keep up-to-date with the work produced by similar organizations. Though they read literature produced by their peer institutions, they are often careful about relying on them for their own work. Because they are not peer reviewed, quality control can be an issue with these reports. One interviewee said that he tries to be very careful when using gray literature because it has not been through a peer review process that would have vetted it for quality. He only uses these reports if they are from organizations he knows and respects (including, but not limited to, governmental agencies), or if they are "think pieces" rather than quantitative studies. One researcher at a Washington, DC, research institute had a similar view: "If you're looking for evidence-based practices, you need research. Those reports are often not research. Sometimes they are and obviously those are good, but often they are syntheses of regular research findings." She feels it is important for her professional knowledge base to be aware of these reports, but she is careful to monitor the quality based on the reputations of the people and institutions involved.

It seems that researchers in research institutes or non-profits have developed various informal methods for sharing gray literature. One researcher at a non-profit said that she sometimes reads about reports from think tanks like Brookings in Education Week, or finds out about them through word-of-mouth, while another told us he generally learns of these reports through a variety of education news digests he receives via e-mail. Another researcher keeps up-to-date on this literature in all these ways as well; she told us about an email list called Penn Weekly and another from an organization called Alliance for Excellence in Education. She also said Education Week often highlights these reports.

\section{Data Sets}

Data is an important component of some research streams outside academia. The government-provided data sets seem important in these settings (especially for less-well-funded organizations), since they are publicly available. One researcher commented that she often needs access to district-specific data for her work. While this data is collected regularly and made public, it is presented differently by every district on their individual home pages, and can be time-consuming to find. Some data-sharing probably occurs

\footnotetext{
${ }^{9}$ In larger organizations like think tanks, the research is often done by assistants and associates, many of whom are likely recent college graduates. Their search methodologies may be
} shaped by their recent education. 
with these audiences, though it likely depends on the project type. One interviewee says that he is extremely careful when using other people's datasets. From producing his own data, he knows how much the choices a researcher makes in collecting and presenting the data can affect its reliability, so he only uses data from scholars or organizations (such as NCES) that he trusts.

\section{Online Communities, Websites, and Listservs}

Unlike the other audiences we've discussed, education researchers outside academic institutions seem to find listservs and electronic newsletters extremely important. Dozens of newsletters and digests exist to consolidate important education news and significant studies released by think tanks and government agencies. Many of these are produced by institutes or other non-profit organizations (for example, the Alliance for Excellence in Education). Some may have particular political bents, but despite this they seem to be valuable mechanisms to disseminate information in this community. 


\section{Resources for In-Practice Teachers and Administrators}

Based on our interviews and secondary research, it seems clear that practitioners - the teachers, administrators, and counselors who do the work that most education research is ultimately trying to influence - rarely read peer reviewed journals. The practitioners we spoke with do not regularly consult journal articles, and professors in education schools did not expect their students to do so after graduation. Several factors contribute to this. Much scholarship is written in a style of academic discourse that nonacademics find impenetrable. Access is a problem, but more important factors are that teachers are far too busy to read scholarly articles, the language of scholarship is inaccessible to a practitioner audience, or the research does not feel directly relevant to a teacher's work. When teachers are exposed to scholarship, it is usually mediated through popular trade publications like Education Week, or through disciplinespecific methods magazines. Teachers generally rely on a preponderance of free online resources, or on their colleagues, for information and assistance. 